\title{
Estruturação ideológica dos partidos e grupos políticos na Venezuela (1998-2000)
}

\author{
Marisa Ramos
}

Universidade de Salamanca

\section{Resumo}

Este artigo analisa a competição política na Venezuela no sentido de avaliar suas possibilidades de estabelecer um sistema partidário relativamente estável e organizar a vida política venezuelana. Estuda o grau de estruturação ideológica e distinções programáticas de alguns partidos relacionados a outros partidos e grupos, como dimensões que contribuem para a escolha eleitoral dos cidadãos.

Os dados provêm da pesquisa "Elites parlamentares na América Latina", dirigida por Manuel Alcântara Sáez, no Instituto de Estudos de Iberoamérica e Portugal, Universidade de Salamanca.

Palavras-chave: Competição política, estruturação ideológica, elites parlamentares, Venezuela

\begin{abstract}
In this article the political competition in Venezuela is analysed in order to evaluate its possibilities to stablish a relatively stable party system and to organize the Venezuelan political life. It studies the level of ideological structuration and programmatic distinctions of some parties related to other parties and groups, as dimensions that contributes to the citizens' electoral choice.

The data become from the research "Parliamentary elites in Latin America", directed by Manuel Alcântara Sáez, in the Institute for Iberoamerica and Portugal Studies, Universidad de Salamanca.
\end{abstract}

Key words: Political competition, ideological structuration, parliamentary elites, Venezuela 


\section{Introdução}

A partir das eleições gerais de 1998, ocorre uma mudança drástica no sistema político venezuelano, que se reflete em diferentes âmbitos institucionais. Um dos indicadores dessa mudança é a profunda transformação do sistema de partidos políticos. Houve uma virada no sistema de partidos, embora a Venezuela fosse considerada durante muito tempo um sistema de partidos estável (Mainwaring \& Scully, 1995). No entanto, a crise de credibilidade e de legitimidade dos partidos chegou a tal profundidade que grande parte do importante êxito eleitoral do Movimento V República (MVR), liderado pelo ex-comandante Hugo Chávez, se explica por esse fator. ${ }^{1}$ Segundo Molina (2001), a identificação negativa com os partidos tradicionais é uma das explicações essenciais do recente comportamento eleitoral.

O sistema de partidos existente até 1998 desmoronou sem que se tenha percebido de forma nítida, até o momento, a estrutura e o formato do novo sistema partidário, ainda em estado embrionário, que o substitui. A alternativa aos partidos tradicionais esteve concentrada, até agora, em um líder "carismático", Hugo Chávez, que catalisa não somente as esperanças de resolver a maior parte dos problemas do país como também, sobretudo, a enorme frustração e desagrado gerados pela "partiarquia" (Coppedge, 1994) que governou nas décadas precedentes. Neste sentido, um dos desafios que o atual sistema político venezuelano enfrenta é precisamente a reconstrução de um sistema partidário em frangalhos. A situação atual está marcada pelo desmoronamento eleitoral dos dois principais partidos tradicionais, AD e COPEI, e pela emergência de diversos grupos políticos e projetos de partido que até o momento não permitem visualizar quais deles terão possibilidades reais de sobrevivência, ${ }^{2}$ como Proyecto Venezuela (PV), ou Primero Justicia, ambos surgidos como projetos de oposição a Chávez e de orientação moderada. Além disso, o condensador da maioria das orientações políticas, o Movimento $\vee$ República, não pode ser considerado um partido político em sentido rigoroso, mas uma plataforma eleitoral que tem como objetivo fundamental acolher a liderança de Chávez e que não apresenta, aparentemente, intenção de organizar-se como partido. ${ }^{3}$

\footnotetext{
${ }^{1}$ Com este fim, pode-se apresentar somento um dado: em 1992, 72\% dos venezuelanos declararam não ser nem militante nem simpatizante de nenhum partido político, segundo a pesquisa em que se apóia o trabalho de Njaim, Combellas e Alvárez (1998).

${ }^{2}$ Ver a esse respeito López Maya (2001).

${ }^{3}$ Este dado entraria em sintonia com as interpretações que ligam o fenômeno da liderança de Chávez e do movimento que o apóia com os fenômenos neopopulistas e antipolíticos, que mostram o desdem pela mesma organização partidária como um dos traços que os definem. Ver a respeito Gómez Calcaño (2000), Roberts (1999) e Kenney (1998), entre outros.
} 
Diante dessa situação, é pertinente analisar a competição política na atualidade para avaliar suas possibilidades de constituir-se em um sistema relativamente estável que permita organizar a vida política venezuelana. Em particular, é especialmente relevante categorizar cada um dos atuais grupos políticos relevantes nessa disputa em termos de partidos ideológicos ou partidos personalistas, utilizando a diferenciação de Coppedge (1998). Mais concretamente, interessa o grau de estruturação ideológica e de diferenciação programática de alguns partidos em relação a outros partidos ou grupos, como dimensões que contribuem para definir os partidos e diferenciá-os do resto e que, portanto, permitem que os cidadãos escolham no momento de votar. Desse modo, neste capítulo, trata-se de analisar o grau de estruturação ideológica dos partidos ou grupos políticos venezuelanos com representação na Assembléia Nacional na atualidade e o grau de diferenciação entre partidos, como forma de conhecer como se estrutura e se define o sistema de partidos surgido das eleições de 2000.

Para realizar este estudo, utilizamos os resultados da pesquisa "Elites parlamentares na América Latina", dirigida por Manuel Alcántara Sáez dentro do Instituto de Estudios de Iberoamérica e Portugal da Universidade de Salamanca. No marco desta pesquisa, foram realizadas cem entrevistas com deputados venezuelanos, segundo uma amostra representativa em consonância com o nível de representação parlamentar de cada grupo, durante os meses de outubro e novembro de 2000. Parte-se da consideração de que os deputados são informantes destacados de seu próprio grupo ou partido e, portanto, fonte de informação essencial para este tipo de análise. ${ }^{4}$ Além disso, provavelmente no caso de mais de um grupo ou partido venezuelano, a arena parlamentar constitui o espaço mais definido de estruturação do funcionamento partidário e que permite um estudo desse funcionamento.

Os resultados das eleições de julho de 2000 e a composição da Assembléia resultante são os seguintes:

\footnotetext{
${ }^{4} \mathrm{Na}$ linha do trabalho realizado, por exemplo, por Kitschelt, Mansfeldova, Markowski e Tóka (1999) para o caso dos países do Leste da Europa.
} 
QUADRO 1

Resultados das eleições para o Congresso Nacional de 1993, 1998 e Assembléia Nacional 2000

Voto por partidos

\begin{tabular}{|l|l|l|}
\hline \multicolumn{2}{|l|}{ Assembléia Nacional } \\
\hline Partido & \multicolumn{2}{l|}{$2000^{\text {(b) }}$} \\
\hline MVR - CONIVE (a) & Votos \% & Assentos \\
MAS (a) & 44.33 & 80 \\
AD & 5.12 & 21 \\
COPEI & 16.10 & 30 \\
Proyecto Venezuela & 5.10 & 8 \\
Primero Justicia & 6.92 & 7 \\
Convergencia-LAPI & 2.46 & 5 \\
Causa R & 1.07 & 4 \\
PPT & 4.41 & 3 \\
Un Nuevo Tiempo & 2.27 & 1 \\
Alianza Bravo Pueblo & 1.75 & 3 \\
Puama & 1.10 & 1 \\
Mi Gato & 0.04 & 1 \\
Apertura & 0.47 & 1 \\
Renovación & & \\
IRENE & & \\
Outros & & 0 \\
\hline
\end{tabular}

(a) Em 2000, embora em alguns casos tenham apresentado candidaturas separadas, o MVR e o MAS integraram uma aliança de caráter nacional. Dessa aliança participaram também outros partidos sem obter assentos. Esses partidos e suas porcentagens de votos em 2000 são os seguintes: PCV (0.36\%); MEP (0.08\%); SI (0.34\%); IPCN (0.17\%); GE (0.11\%) e NRD (0.10\%). Estes partidos minoritários estão agrupados na Tabela com o resto que não obteve assentos, na categoria "Outros" (Molina, 2000)

Fontes: Molina (2001); Consejo Supremo Electoral; Consejo Nacional Electoral. Resultados Electorales 1998. Consejo Nacional Electoral-INDRA, Página Web, Resultados Electorales de 2000.

Para construir as dimensões ideológicas, utilizam-se quatro grandes blocos de temas ou issues. Um deles é constituído por uma superdimensão amplamente utilizada há muito tempo, que é a dimensão esquerda-direita. Embora se tenha questionado abundantemente as possibilidades de aplicação dessa dimensão na América Latina, estudos mais recentes mostraram a pertinência desse tipo de escala (Alcántara, 1995, Coppedge, 1998). Desse modo, a localização e a autolocalização dos deputados em uma escala que mede esta dimensão ideológica será o primeiro bloco de informação. Um segundo bloco de definição ideológica está composto por uma série de perguntas que pretendem medir as atitudes dos deputados em relação ao sistema democrático em geral e em relação ao sistema 
venezuelano atual em particular, para determinar a existência de componentes autoritários dentro da elite política. O terceiro bloco indaga sobre as visões que os deputados têm sobre a intervenção do Estado na economia. O último bloco é composto pela definição em torno do grau de religiosidade, tema que apresenta freqüentemente comportamentos transversais nos deputados, para além das identificações políticas (o texto das perguntas utilizadas na análise está em anexo no final do artigo).

O artigo está dividido em três partes. Na primeira, apresenta-se a localização dos partidos e grupos políticos dentro das dimensões antes apontadas. Tem, portanto, um fim fundamentalmente descritivo. A segunda parte pergunta sobre a validade da dimensão esquerda-direita como índice de estruturação do resto de definições ideológicas. Em outros termos, trata-se de investigar os conteúdos que a dimensão esquerda-direita tem para o caso venezuelano. Portanto, as variáveis antes apontadas serão relacionadas. A terceira parte do artigo aborda as diferenças ideológicas entre partidos, destacando as dimensões que contribuem para distingui-los e, portanto, que são suscetíveis de se constituir em "cleavages" que estruturem um sistema de partidos ainda embrionário. A forma de abordar esta parte será através das diferenças de médias aritméticas de cada grupo ou partido político com representação na Assembléia Nacional nas distintas perguntas analisadas. Finalmente, apresentaremos algumas conclusões.

\section{A estruturação em torno da dimensão esquerda-direita}

Tal como dissemos antes, a dimensão esquerda-direita continua um instrumento válido para estruturar a competição política entre partidos. A aplicação dessa dimensão na América Latina foi questionada com freqüência, embora isso não tenha impedido que se continue a utilizá-la. ${ }^{5} \mathrm{~A}$ verdade é que, a primeira vista, é difícil estruturar a competição política venezuelana atual utilizando essa dimensão. Os partidos existentes não parecem ser facilmente classificáveis nesses termos, ainda que os deputados venezuelanos se identificassem maciçamente dentro deste parâmetro, de forma que a porcentagem de respostas "não sabe/não responde" nesta pergunta foi muito pequena.

A Assembléia Nacional atual se situa de forma majoritária na esquerda do espectro ideológico, pois quase $80 \%$ se situam à esquerda da escala e $65 \%$ se situam no ponto 3 ou no 4 dessa mesma escala. A autolocalização média é 4.33 em uma escala na qual 1 é o ponto máximo na esquerda e 10 o ponto máximo na direita. A localização média dos partidos segundo as respostas de seus deputados em relação à localização de seu próprio partido é 4,75 . Isso significa que a maioria

\footnotetext{
${ }^{5}$ Para o caso venezuelano, ver, por exemplo, Molina (2000).
} 
dos deputados se considera de esquerda moderada e que, em geral, situam a si mesmos um pouco mais à esquerda do que situam seu próprio partido. Por partidos ou grupos, os deputados do MVR são os que se situam mais à esquerda, com uma autolocalização média de 3,64 na escala e de 4,10 de seu partido. Em seguida vêm os deputados do MAS $(3,83)$, que situam de forma igual seu partido; a $A D$, com uma autolocalização de 5,56 está muito próxima da autolocalização dos deputados do COPEI $(5,83)$. Finalmente, os deputados do Proyecto Venezuela são os que se autolocalizam mais à direita, situando-se no ponto 6,50 . É preciso destacar que, enquanto os deputados da AD e do MAS se situam praticamente no mesmo ponto que seu partido, os membros de outros grupos se autolocalizam mais à esquerda que seu partido: 3,57 contra 4,10 no MVR; 5,83 contra 7,00 no COPEI e 6,50 contra 7,00 no Proyecto Venezuela.

\section{GRÁFICO 1}

\section{Localização dos deputados na escala esquerda-direita}

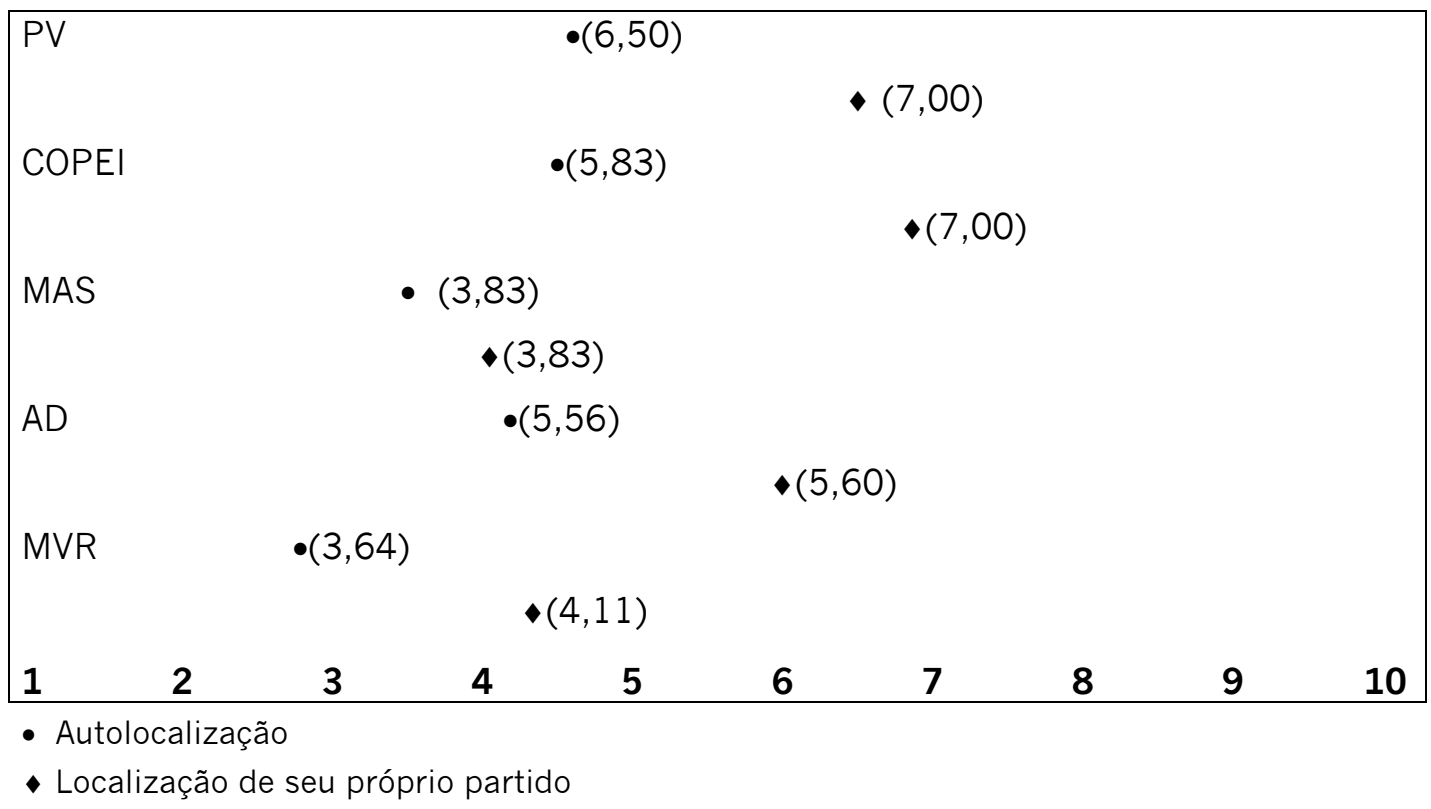

Analisando o Gráfico I, podemos extrair algumas apreciações sobre a competição entre partidos ou grupos. Utilizando-se a autolocalização média na escala esquerda-direita, podemos perceber de forma nítida a superposição entre grupos políticos. O MVR seria o grupo que menos se superpõe, pois ocupa na escala grande parte do espaço de esquerda, compartilhado somente com o MAS. O mesmo sucede no outro extremo com o Proyecto Venezuela, que só compartilha uma parte 
de seu espaço com o COPEI. No entanto, os dois partidos tradicionais compartilham seu espaço com todos os outros partidos, de forma que não têm nenhum espaço ocupado com exclusividade.

É destacável a superposição entre os dois partidos ou grupos em coalizão de governo e os da oposição. Enquanto os primeiros se situam no espaço da esquerda moderada, os partidos da oposição se superpõem no espaço do centro, com uma ligeira inclinação para a direita do Proyecto Venezuela. Esses dados mostram claramente dois fenômenos. Em primeiro lugar, que o MVR, com uma representação na Assembléia de mais de 50\%, ocupa no espectro ideológico uma faixa limitada da esquerda que vai do ponto 2 ao 5 , com um ponto médio de localização em 3,83.

Em segundo lugar, existem superposições entre partidos, de forma que há mais do que um partido ocupando o mesmo espaço e espaços que não estão ocupados por nenhum partido. Em especial, existe um solapamento quase perfeito entre o MVR e o MAS, de um lado, e entre AD, COPEI e Proyecto Venezuela de outro, de forma que finalmente, em relação à localização nesta escala, existem dois grandes blocos ideológicos que, no entanto, não correspondem à existência de dois grandes blocos ou partidos. Sem dúvida, a competição interna entre os partidos da oposição é afetada por esse solapamento.

Esses dados são compatíveis com os oferecidos por Molina (2000), segundo os quais a estabilidade do comportamento eleitoral dos venezuelanos existe, mas não agora no marco da identificação partidária, mas da ideologia, de forma que os eleitores continuam se mantendo em posições estáveis no espectro esquerdadireita. Desta maneira, apesar da volatilidade eleitoral das preferências em relação aos partidos, existe um setor do eleitorado numericamente importante que se mantém leal à sua localização ideológica, existindo mais de um partido que compete pelo mesmo espaço ideológico.

Para dar conteúdo à variável esquerda-direita, identificando as dimensões que a estruturam, realizou-se uma análise de regressão, utilizando a variável da autolocalização na escala esquerda-direita como variável dependente. Os resultados são os seguintes: 


\section{Regressão Linear}

Variável dependente:

Autolocalização na escala esquerda direita (IZQDER)

Variáveis independentes:

Partidos políticos e democracia (PARTDEMO)

Confiança em eleições (CONFIELEC)

Avaliação do papel das Forças Armadas (EVALUFAS)

Regulação Estado-mercado da economia (ESTAMERC)

Grau de religiosidade (RELIGIOS)

\begin{tabular}{|c|c|c|c|c|c|}
\hline \multirow[t]{2}{*}{ Modelo } & \multicolumn{2}{|c|}{ Coeficientes não estandartizados } & \multirow{2}{*}{$\begin{array}{c}\begin{array}{c}\text { Coeficientes } \\
\text { estandartizados }\end{array} \\
\text { Beta }\end{array}$} & \multirow[b]{2}{*}{$t$} & \multirow[b]{2}{*}{ Sig. } \\
\hline & $B$ & Erro padrão. & & & \\
\hline (Constante) & 5.576 & .843 & & 6.612 & .000 \\
\hline PARTDEMO & -.355 & .133 & .255 & -2.676 & .009 \\
\hline CONFIELEC & $\cdot .312$ & .138 & .233 & -2.266 & .026 \\
\hline EVALUFAS & -166 & .050 & -.838 & -3.292 & .001 \\
\hline ESTAMERC & .259 & .234 & -.133 & 1.108 & .271 \\
\hline RELIOGIOS & -1446 & .053 & .747 & 2.727 & .008 \\
\hline
\end{tabular}

R: .518

$R^{2}: 269$

$R^{2}$ ajustado: .230

Erro padrão da estimativa 1.64

Conforme estes dados, investiga-se a diferenciação entre partidos em torno desses quatro grandes blocos: a atitude em relação ao sistema político democrático, a avaliação do regime atual, a percepção da intervenção econômica do Estado e o grau de religiosidade.

\section{As dimensões ideológicas dos grupos políticos}

\section{As atitudes em relação ao sistema político democrático}

Diante dos dados que o Quadro 2 oferece, destaca-se o fato de que, embora haja consenso entre todos os grupos quanto à democracia ser preferível a qualquer outra forma de governo, entre os deputados do MVR existe uma pequena porcentagem que pensa que, em determinados contextos políticos ou sociais, pode ser preferível um governo autoritário. Levando em conta a disseminação da idéia de democracia na América Latina durante as últimas décadas, chama a atenção que $16 \%$ dos deputados do MVR possam, eventualmente e em determinadas circunstâncias, apoiar um governo autoritário. Nesse aspecto, a diferença do MVR para o resto dos grupos políticos com representação na Assembléia Nacional é essencial para apreender as chaves da competição entre partidos. 
OPINIÃO PÚBLICA, Campinas, Vol. VIII, n², pp.230-250

\section{QUADRO 2}

Atitude em relação ao sistema político democrático (\%)

\begin{tabular}{|l|l|c|c|c|c|c|}
\cline { 3 - 7 } \multicolumn{2}{c|}{} & MVR & AD & MAS & COPEI & PV \\
\hline $\begin{array}{l}\text { Democracia sempre ou } \\
\text { autoritarismo em circunstâncias } \\
\text { especiais }\end{array}$ & Democracia & 84,1 & 100 & 100 & 100 & 100 \\
\cline { 2 - 7 } & Autoritarismo & 15,9 & $\cdot$ & $\cdot$ & $\cdot$ & $\cdot$ \\
\hline $\begin{array}{l}\text { Sem partidos não pode haver } \\
\text { democracia }\end{array}$ & Acordo & 47,8 & 93,8 & 75 & 83,3 & 75 \\
\cline { 2 - 7 } & Desacordo & 52,2 & 6,3 & 25 & 16,7 & 25 \\
\hline $\begin{array}{l}\text { As eleições são sempre o melhor } \\
\text { método de expressar diferenças } \\
\text { políticas }\end{array}$ & Acordo & 80,4 & 87,5 & 100 & 100 & 100 \\
\hline & Desacordo & 19,2 & 12,5 & $\cdot$ & $\cdot$ & $\cdot$ \\
\hline $\mathrm{N}=$ & & 47 & 15 & 12 & 6 & 4 \\
\hline
\end{tabular}

Também é destacável a diferença do MVR com respeito às outras agremiações no que se refere à idéia de que sem partidos também pode haver democracia (ver Quadro 3). Com efeito, mais da metade dos deputados do MVR está em desacordo com esta afirmação, isto é, não consideram os partidos instituições imprescindíveis para um sistema democrático. Ao contrário, a imensa maioria dos deputados dos outros grupos está de acordo com a premissa da impossibilidade da democracia sem partidos (maioria que aumenta significativamente entre os deputados dos partidos tradicionais, AD e COPEI). É um dado conhecido o desinteresse do MVR e, sobretudo, de seu líder, Hugo Chávez, por organizar-se como partido político, tal como mostrou claramente López Maya (2000), traço que constituiria um indicador da conexão desse tipo de movimento com os fenômenos denominados neopopulistas, que têm entre suas características essenciais o desprezo pela organização de partido (ver Kenney, 1998 ou Shedler, 1996) ${ }^{6}$ e, em geral, a tentativa de transgressão dos limites institucionais democráticos quando estes não Ihes são úteis. ${ }^{7}$

Há um relativo consenso entre todos os grupos de que as eleições são sempre o melhor meio de expressar as diferenças políticas. Nesta mesma linha, de novo os deputados do MVR são os menos inclinados a concordar com a afirmação. Entre o resto, há consenso absoluto entre os deputados do MAS, COPEI e Proyecto Venezuela, enquanto que $12.5 \%$ dos deputados de AD estão em desacordo.

\footnotetext{
${ }^{6}$ López Maya (2000) enfatiza esta idéia citando o presidente Chávez: "Nenhum partido político me tira o sono; o que me tira o sono é a organização do movimento popular... Os partidos devem ser expressão desse movimento popular, devem ser canais de participação e de influência do movimento popular organizado, mas não pode ser hegemonizado. Se não servem, bem, o movimento popular deve envolvê-los... Os partidos para mm são como ensaios" (Chávez, entrevista, El Nacional, 1212-1999; D-1)

${ }^{7}$ Sobre o discurso ideológico de Chávez e suas conexões com o fenômeno do populismo, ver Lazo (2000).
} 
QUADRO 3

Atitudes em relação ao sistema democrático

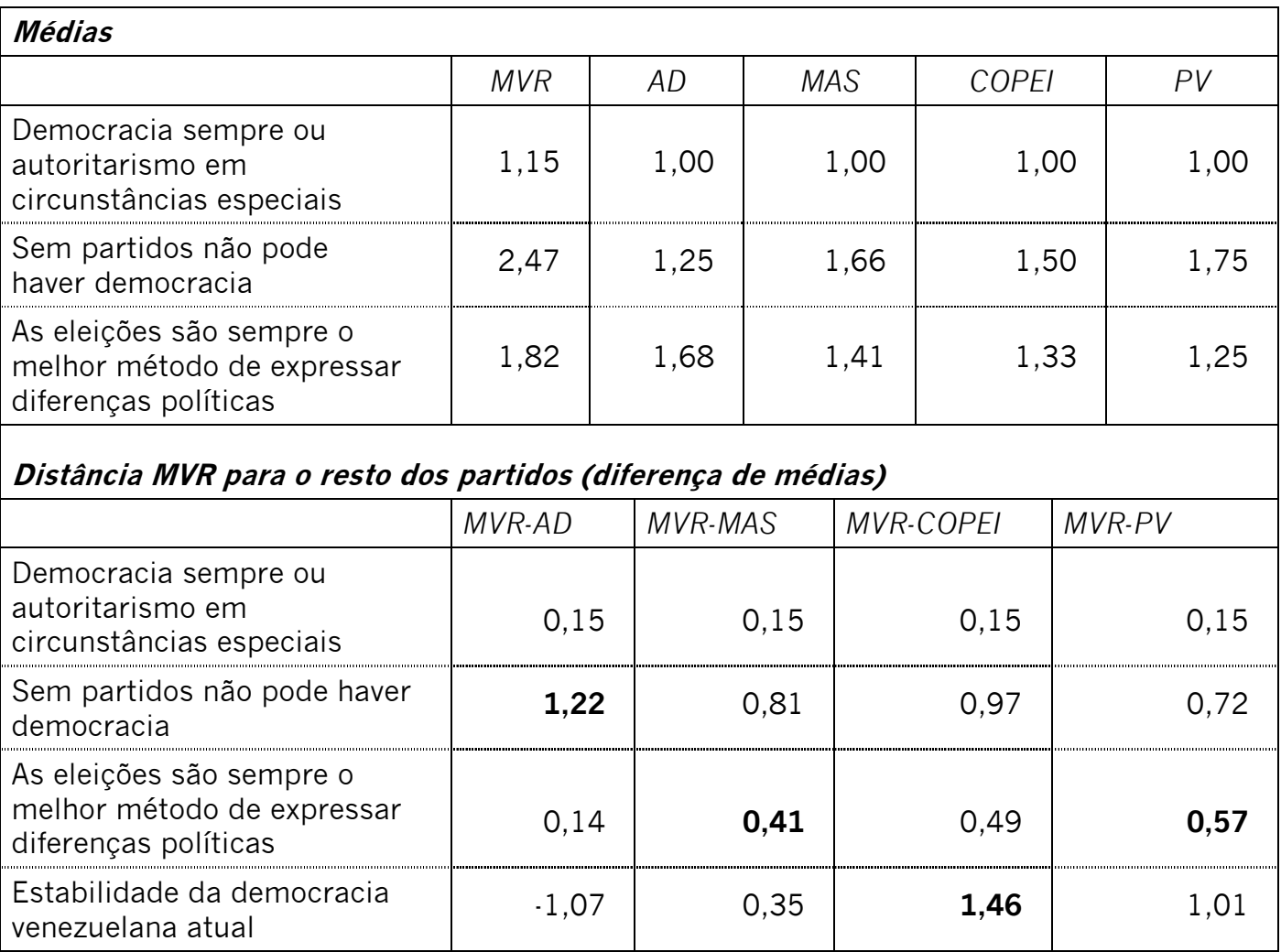

\section{Avaliação do sistema político atual}

No que se refere à avaliação do sistema político venezuelano atual, conforme os dados do Quadro 4, dois terços dos deputados venezuelanos percebem a democracia atual como um sistema estável ou muito estável. Porém, estabelecendo-se as diferenças por partidos, se observa um enorme dissenso quanto à percepção da estabilidade da democracia. Assim, enquanto 93,1\% dos integrantes do MVR a avaliam como estável e muito estável, $100 \%$ dos integrantes do COPEl têm uma percepção oposta, como pouco ou nada estável. Quanto ao outros grupos, os de oposição avaliam de forma claramente negativa a percepção da estabilidade da democracia, enquanto que o MAS apresenta percepções mais positivas, pois mais de $70 \%$ consideram que a democracia é estável ou muito estável. Em referência a esta percepção, a diferença baseia-se logicamente entre ser partido de governo ou aliado do governo ou ser partido de oposição. 
OPINIÃO PÚBLICA, Campinas, Vol. VIII, no2, pp.230-250

Na mesma linha, há uma relativa falta de consenso no que se refere à consideração de problemas que poderiam constituir-se em ameaças para a democracia na Venezuela. Assim, há temas que geram consenso, enquanto que outros produzem dissenso. Entre os primeiros, a maior parte dos deputados considera a pobreza, a insegurança dos cidadãos e a crise econômica ameaças potenciais para a democracia, bem como o mau funcionamento do poder judiciário. No outro extremo, a violência política é considerada uma ameaça importante pela maioria dos deputados. Os dissensos acontecem na hora de avaliar aspectos como as relações entre as Forças Armadas e o governo, que é considerado um problema de muita importância por mais da metade dos integrantes dos partidos de oposição, enquanto que quase $90 \%$ dos deputados do MVR não percebem que este seja um assunto importante. Igualmente, o desinteresse pela política é avaliado de forma distinta pelos deputados do MVR e MAS e dos partidos de oposição, pois enquanto mais da metade dos primeiros estima que não é uma ameaça importante, entre $70 \%$ e $100 \%$ dos deputados da AD e do COPEI estimam este assunto como um problema de primeira ordem.

\section{QUADRO 4}

Avaliação do sistema político venezuelano atual (\%)

\begin{tabular}{|l|l|r|r|r|c|c|}
\cline { 3 - 7 } \multicolumn{2}{l|}{} & MVR & AD & MAS & COPEI & PV \\
\hline $\begin{array}{l}\text { Estabilidade da } \\
\text { democracia } \\
\text { venezuelana atual }\end{array}$ & Estável e muito estável & 93,1 & 31,3 & 72,7 &. & 25 \\
\hline $\mathrm{N}=$ & Pouco estável e nada estável & 6,9 & 68,8 & 27,3 & 100 & 75 \\
\hline
\end{tabular}

\section{QUADRO 5}

Ameaças para a democracia (\%)

\begin{tabular}{|l|l|l|l|l|l|l|l|l|l|l|}
\hline \multirow{2}{*}{$\begin{array}{l}\text { Importância } \\
\begin{array}{l}\text { concedida aos } \\
\text { seguintes aspectos }\end{array}\end{array}$} & \multicolumn{2}{|c|}{ MVR } & \multicolumn{2}{c|}{ AD } & \multicolumn{2}{c|}{ MAS } & \multicolumn{2}{c|}{ COPEI } & \multicolumn{2}{c|}{ PV } \\
\cline { 2 - 12 } \\
\hline $\begin{array}{l}\text { Relações FAS e } \\
\text { governo }\end{array}$ & 10,7 & 89,3 & 60 & 40 & 41,6 & 58,3 & 50 & 50 & 75 & 25 \\
\hline Crise econômica & 78,2 & 21,7 & 100 & - & 66,6 & 33,4 & 100 & - & 100 &. \\
\hline $\begin{array}{l}\text { Terrorismo e } \\
\text { violência política }\end{array}$ & 36,2 & 63,8 & 62,5 & 37,5 & 16,7 & 83,3 & 16,7 & 83,4 & 25 & 75 \\
\hline $\begin{array}{l}\text { Mau funcionamento } \\
\text { do poder judiciário }\end{array}$ & 80,8 & 19,2 & 93,3 & 6,7 & 66,7 & 33,3 & 100 &. & 100 &. \\
\hline $\begin{array}{l}\text { Insegurança dos } \\
\text { cidadãos }\end{array}$ & 74,4 & 23,4 & 81,3 & 18,8 & 75 & 25 & 100 &. & 50 & 50 \\
\hline Pobreza & 87,2 & 12,8 & 93,8 & 6,3 & 83,4 & 16,6 & 83,4 & 16,7 & 100 &. \\
\hline $\begin{array}{l}\text { Desinteresse pela } \\
\text { política }\end{array}$ & 42,5 & 57,4 & 68,8 & 31,3 & 33,3 & 66,6 & 100 & - & 50 & 50 \\
\hline N = & 47 & & 15 & & 12 & & 6 & & Pouca \\
\hline
\end{tabular}


Utilizando-se como indicador inicial de diferenciação entre partidos a diferença de médias em torno desses itens, o Quadro 5 mostra que a distância ou diferença maior do MVR para o resto dos partidos se estabelece com a AD e com o COPEI, no capítulo que se refere à atitude quanto ao sistema democrático. Com a primeira, existem diferenças importantes quanto à necessidade de partidos políticos para que exista democracia, diferença que também é apreciável com o COPEI. Com este último partido existe uma diferença de médias importante no que tange à valoração da estabilidade da democracia em Venezuela na atualidade, também significativa com a $A D$ e com o Proyecto Venezuela. Estas diferenças não são tão destacáveis no que se refere à avaliação das eleições como forma de expressar sempre as preferências políticas. As diferenças do MVR para o MAS são muito menores.

\section{QUADRO 6}

\section{Ameaças para a democracia}

\begin{tabular}{|c|c|c|c|c|c|}
\hline \multicolumn{6}{|l|}{ Médias } \\
\hline $\begin{array}{l}\text { Importância concedida aos } \\
\text { seguintes aspectos }\end{array}$ & $M V R$ & $A D$ & MAS & COPEI & $P V$ \\
\hline Relações FAS e governo & 3,57 & 1,93 & 2,75 & 2,50 & 2,25 \\
\hline Crise econômica & 1,71 & 1,18 & 1,91 & 1,16 & 1,00 \\
\hline Violência política & 2,82 & 2,00 & 3,41 & 3,50 & 2,75 \\
\hline $\begin{array}{l}\text { Mau funcionamento do } \\
\text { poder judiciário }\end{array}$ & 1,68 & 1,46 & 2,00 & 1,33 & 1,00 \\
\hline Insegurança dos cidadãos & 1,87 & 1,56 & 1,83 & 1,33 & 2,25 \\
\hline Pobreza & 1,51 & 1,25 & 1,58 & 1,66 & 1,00 \\
\hline Desinteresse pela política & 2,65 & 1,87 & 2,75 & 1,50 & 2,50 \\
\hline \multicolumn{6}{|c|}{ Distância MVR para o resto dos partidos } \\
\hline & $M V R-A D$ & MVR-MAS & \multicolumn{2}{|c|}{ MVR-COPEI } & MVR-PV \\
\hline Relações FAS e governo & 1.64 & 0.82 & & 1.07 & 1.32 \\
\hline Crise econômica & 0.53 & -0.2 & & 0.55 & 0.71 \\
\hline Violência política & 0.82 & .0 .59 & & .0 .68 & 0.07 \\
\hline $\begin{array}{l}\text { Mau funcionamento do poder } \\
\text { judiciário }\end{array}$ & 0.22 & .0 .32 & & 0.35 & 0.68 \\
\hline Insegurança dos cidadãos & 0.31 & 0.04 & & 0.54 & -0.38 \\
\hline Pobreza & 0.26 & -0.07 & & .0 .15 & 0.51 \\
\hline Desinteresse pela política & 0.78 & -0.1 & & 1.15 & 0.15 \\
\hline
\end{tabular}


Quanto às percepções de risco para a democracia, com base no Quadro 6, percebem-se as diferenças entre o MVR e o resto dos partidos fundamentalmente em referência à importância concedida à relação entre as FAS e o governo, onde diferença MVR e AD é especialmente importante. Também destacáveis são as diferenças do MVR para $A D$ e COPEI no que tange à gravidade atribuída a problemas como o do desinteresse pela política, o da violência política ou o da crise econômica. As diferenças mais acusadas se dão sempre com a AD e com o COPEI, especialmente com esta última formação. De novo, as diferenças do MVR para o MAS não são significativas.

As diferenças da $A D$ para o resto dos partidos de oposição são pouco importantes em geral, pouco mais pronunciadas com o Proyecto Venezuela que com o COPEI. Com esta última agremiação, a AD mantém posições bem distintas no que se refere à percepção como ameaça para a democracia do problema da violência política, enquanto que no resto dos items as posições são similares. As diferenças da $A D$ para o MAS são mais fortes, equiparáveis, em todo caso, às apresentadas com o MVR.

\section{A intervenção do Estado na economia}

De acordo com os dados que aparecem no Quadro 8, relativos ao modelo de regulação econômica mercado, os mais estatistas são os deputados do MAS e do MVR, ao passo que os mais liberais correspondem ao Proyecto Venezuela e ao COPEI. É significativo que nenhum deputado da AD, do COPEI ou do Proyecto Venezuela se situe em posições estatistas, sendo a porcentagem destes de $8.7 \%$ entre os do MVR ou de $7.7 \%$ entre os do MAS. Sem dúvida, a experiência de política econômica sumamente intervencionista gerou uma atitude de rechaço importante, inclusive entre os deputados que se autoclassificam de forma nítida na esquerda.

Ao perguntar sobre dois itens que concretizam estas posições (Quadro 7), a intervenção do Estado no controle de preços e na geração de pleno emprego, os resultados são relativamente coerentes com os antes mencionados. Uma porcentagem importante de todos os deputados considera que o Estado deve intervir muito nesses dois aspectos, especialmente no que tange a gerar pleno emprego. Por partidos, os mais intervencionistas são os deputados do MVR e do MAS e os menos, os do Proyecto Venezuela e COPEl. Chama a atenção a disparidade no interior dos partidos, revelando o desconcerto existente entre as opções intervencionistas próprias do Estado do bem-estar e a experiência venezuelana de Estado sumamente protetor. 


\section{QUADRO 7}

Intervenção econômica do Estado I

\begin{tabular}{|l|l|l|l|l|l|l|l|l|l|l|}
\hline \multirow{2}{*}{} & \multicolumn{2}{|c|}{ MVR } & \multicolumn{2}{c|}{ AD } & \multicolumn{2}{c|}{ MAS } & \multicolumn{2}{c|}{ COPEI } & \multicolumn{2}{c|}{ PV } \\
\cline { 2 - 11 } & Muita & Pouca & Muita & Pouca & Muita & Pouca & Muita & Pouca & Muita & Pouca \\
\hline $\begin{array}{l}\text { Intervenção do } \\
\text { Estado no controle } \\
\text { dos preços }\end{array}$ & 67,4 & 32,6 & 8,3 & 89,5 & 33,3 & 66,6 & 50 & 50 &. & 100 \\
\hline $\begin{array}{l}\text { Intervenção do } \\
\begin{array}{l}\text { Estado na geração } \\
\text { de pleno emprego }\end{array}\end{array}$ & 76,6 & 23,4 & 47,4 & 52,7 & 58,4 & 41,7 & 25 & 75 & 25 & 75 \\
\hline Emprego & & & & & & & & & & \\
\hline $\mathrm{N}=$ & 47 & & 15 & & 12 & & 6 & & 4 \\
\hline
\end{tabular}

\section{QUADRO 8}

Intervenção econômica do Estado II

\begin{tabular}{|l|c|c|c|c|c|c|c|c|c|c|}
\hline & \multicolumn{2}{|c|}{ MVR } & \multicolumn{2}{c|}{ AD } & \multicolumn{2}{c|}{ MAS } & \multicolumn{2}{c|}{ COPEI } & \multicolumn{2}{c|}{ PV } \\
\cline { 2 - 10 } & $\begin{array}{c}\text { Esta- } \\
\text { do }\end{array}$ & $\begin{array}{c}\text { Merca- } \\
\text { do }\end{array}$ & $\begin{array}{c}\text { Esta- } \\
\text { do }\end{array}$ & $\begin{array}{c}\text { Merca- } \\
\text { do }\end{array}$ & $\begin{array}{c}\text { Esta- } \\
\text { do }\end{array}$ & $\begin{array}{c}\text { Merca- } \\
\text { do }\end{array}$ & $\begin{array}{c}\text { Esta- } \\
\text { do }\end{array}$ & $\begin{array}{c}\text { Merca- } \\
\text { do }\end{array}$ & $\begin{array}{c}\text { Esta- } \\
\text { do }\end{array}$ & $\begin{array}{c}\text { Merca- } \\
\text { do }\end{array}$ \\
\hline $\begin{array}{l}\text { Economia } \\
\text { regulada } \\
\text { pelo Estado } \\
\text { ou pelo } \\
\text { mercado* }\end{array}$ & 8,7 & 13 & - & 45 & 7,7 & 7,7 & - & 66, & - & 100 \\
\hline $\mathrm{N}=$ & 47 & & 15 & & 12 & & 6 & & 4 & \\
\hline
\end{tabular}

* Em uma escala de valores de 1 a 5, sendo 1 a máxima regulação estatal e 5 a máxima regulação pelo mercado, incluem-se somente as porcentagens correspondentes aos valores 1 e 2, recodificados como "Estado" e os valores 4 e 5, recodificados como "Mercado".

\section{QUADRO 9}

Intervenção econômica do Estado

\begin{tabular}{|l|c|c|c|c|c|}
\hline Médias \\
\hline & $M V R$ & $A D$ & $M A S$ & COPEI & $P V$ \\
\hline Controle de preços & 2,04 & 3,06 & 3,00 & 3,00 & 3,50 \\
\hline Geração de pleno emprego & 1,74 & 2,37 & 2,17 & 2,83 & 2,75 \\
\hline Estado-mercado & 3,09 & 3,63 & 3,08 & 4,00 & 4,25 \\
\hline \\
Distância MVR para o resto dos partidos \\
\hline \multicolumn{7}{|l|}{ MVR-AD } & MVR-MAS & MVR-COPEI & MVR-PV \\
\hline Controle de preços & 1,02 & 0,96 & 0,96 & 1,46 \\
\hline Geração de pleno emprego & 0,63 & 0,43 & 1,09 & 1,01 \\
\hline Estado-mercado & 0,54 & 0,01 & 0,91 & 1,41 \\
\hline
\end{tabular}




\section{Grau de religiosidade}

Quanto ao grau de religiosidade (Quadro 10), os mais religiosos são os deputados do Proyecto Venezuela e os menos, os do MAS. Observa-se, no entanto, que em todos os grupos existe um grupo significativo de deputados que se consideram muito religiosos.

QUADRO 10

Grau de religiosidade (\%)

\begin{tabular}{|l|c|c|c|c|c|}
\hline & MVR & $A D$ & MAS & COPEI & PROY. VENEZ \\
\hline Mínima & 43,5 & 44,5 & 58,3 & 16,7 & 25,0 \\
\hline Média & 43,5 & 22,5 & 33,3 & 50,1 & 25,0 \\
\hline Máxima & 13,0 & 11,2 & 8,3 & 33,4 & 50,0 \\
\hline $\mathrm{N}=$ & 47 & 16 & 12 & 5 & 4 \\
\hline
\end{tabular}

QUADRO 11

Grau de religiosidade

\begin{tabular}{|c|c|c|c|c|}
\hline MVR & $A D$ & MAS & COPEI & $P V$ \\
\hline 4,22 & 4,37 & 3,33 & 6,33 & 6,00 \\
\hline
\end{tabular}

Diferenças MVR para o resto (diferença de médias)

\begin{tabular}{|c|c|c|c|}
\hline MVR-AD & MVR-MAS & MVR-COPEI & MVR-PV \\
\hline 0,15 & 0,89 & 2,11 & 1,78 \\
\hline
\end{tabular}

\section{Conclusões}

Diante dos dados utilizados, percebem-se algumas tendências que podem servir como indicadores das dimensões que estruturam o atual sistema de partidos. No que se refere às dimensões ideológicas dos distintos partidos e grupos, há uma tendência à localização na esquerda moderada, mais pronunciada no caso da autolocalização do que no da localização do partido. A diferença entre a autolocalização e a localização ideológica de seu próprio partido é destacável entre os deputados do COPEI e, em menor medida, entre os deputados do MVR.

Por outra parte, existe um relativo consenso acerca das boas qualidades do sistema democrático representativo. O dissenso se percebe no MVR, no qual podem ocorrer opções compreensivas com os governos autoritários se as circunstâncias o justificarem, assim como idéias, relativamente generalizadas, que podem aceitar um sistema sem partidos políticos ou que existam outras formas de tomar decisões que não seja a eleição. 
Quanto à avaliação do sistema político venezuelano atual, o MVR e o MAS consideram que a democracia na Venezuela é estável ou muito estável, ao passo que a maioria do resto dos partidos tem opinião justamente oposta, julgando ser pouco ou nada estável. Da mesma forma, também se percebem de forma distinta os problemas que o país enfrenta. Enquanto existe um consenso em qualificar como muito graves todos os problemas relacionados com a situação econômica e social da população (pobreza, crise, insegurança do cidadão), a percepção, por parte dos partidos de oposição, de outro tipo de assuntos relacionados com a vida política (desinteresse pela política ou relações entre as Forças Armadas e o governo) como problemas importantes contrasta com a escassa importância atribuída a eles pelo MVR ou pelo MAS.

Em relação ao papel do Estado na economia ou na sociedade, MVR, MAS e $A D$ são, em geral, intervencionistas, ao passo que o COPEI e o Proyecto Venezuela se situam em posições mais próximas à que defende o encolhimento do Estado. Porém, é interessante destacar que tanto a AD como o COPEI oferecem posições mais contraditórias ao tratar de concretizar em itens essa intervenção, especialmente no que se refere à intervenção do Estado na criação de cobertura de desemprego. Finalmente, no aspecto relacionado com o divórcio ou o aborto, MAS e MVR são os grupos mais liberais enquanto que COPEI e Proyecto Venezuela apresentam as posições mais conservadoras. De novo, AD é relativamente dispersa neste aspecto.

Quanto aos níveis de coerência interna que apresenta cada grupo, é preciso assinalar que se percebem níveis de dispersão importantes no que tange à localização esquerda-direita, na atitude perante a democracia e a avaliação do sistema político venezuelano ou nas questões morais. Em relação ao papel do Estado, os níveis de coerência interna são maiores. A AD é a mais dispersa na hora de localizar-se na escala esquerda e direita, enquanto que o MVR apresenta os maiores índices de dispersão interna em relação a avaliação do sistema democrático representativo em geral. No que diz respeito à avaliação do sistema político atual na Venezuela, o MAS não é em absoluto homogêneo em suas respostas e o COPEI apresenta níveis semelhantes de dispersão no que tange à intervenção do Estado na economia ou na sociedade.

Finalmente, conforme as posições ideológicas de cada grupo ou partido, podem-se apontar tendências de divisões entre partidos ou de linhas de diferenciação que podem contribuir para estruturar a competição entre partidos. Percebe-se um preocupante solapamento entre partidos ao longo da escala esquerda-direita, de forma que vários partidos competem pelos mesmos espaços. 0 solapamento é quase total no caso do MAS e MVR por um lado, e no caso da AD e do COPEI, por outro. De acordo com isso, é previsível que ocorram no futuro 
deslocamentos ou desaparições de partidos, se utilizarmos a escala esquerdadireita como indicador ideológico.

Outros aspectos que contribuem para diferenciar os partidos são, por exemplo, a percepção do modelo de democracia representativa, do papel dos partidos políticos ou das eleições. Nesses aspectos, o MVR se situa de forma relativamente distinta à expressa pelos partidos da oposição, sobretudo a $A D$ e o COPEI, muito mais comprometidos com essa forma de governo. Também contribui para gerar diferenças a percepção dos problemas da vida política, pois enquanto para os partidos AD, COPEl e Proyecto Venezuela as relações das Forças Armadas e - governo ou o desinteresse do povo pela política são assuntos de suma importância que podem, inclusive, constituir-se em uma ameaça à democracia, para o MVR e o MAS, estas questões não apresentam gravidade no momento atual. Por último, o papel do Estado e as posições acerca do divórcio ou do aborto não constituem um aspecto de diferenciação importante, como seria previsível. Apenas alguns itens concretos, como o seguro de desemprego ou a opinião sobre o aborto, contribuem para gerar diferenças, embora neste caso, não se possa estabelecer uma divisão tão clara entre partidos de governo e partidos de oposição como nos aspectos antes comentados.

\section{BIBLIOGRAFIA}

ALCÁNTARA, Manuel. (1995) La élite parlamentaria latinoamericana y el continuo izquierdaderecha. In: HOFMEISTER, W. \& THERING J. (eds.). Transformación de los sistemas políticos en América Latina. Buenos Aires, Konrad Adenauer Stiftung.

COPPEDGE, Michael. (1994) Strong parties and Lame Ducks. Presidential Partyarchy and Factionalism in Venezuela. Stanford, Stanford University Press.

Politics, 4:547-568 (outubro). (1998) The Dynamic Diversity of Latin American Party Systems. Party

GÓMEZ CALCAÑO, Luis \& ARENAS, Nelly. (2000) Modernización autoritaria o actualización de populismo? La transición política en Venezuela. Trabalho apresentado no Simpósio "Democracia en las Américas: desafíos, peligros y expectativas para el siglo XXI" no $50^{\circ}$ Congresso Internacional de

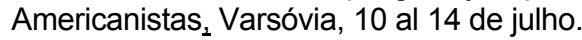

KENNEY, Charles. (1998) Anti-políticos, intrusos y política democrática. é Politiké, ano II, n 3:28-42.

KITSCHELT, Herbert, MANSFELDOVA, Zdenka, MARKOWSKI, Radoslaw \& TÓKA, Gábor. (1999) Post-Communist Party Systems. Cambridge, Cambridge University Press.

LAZO CIVIDANES, Jorge. (2000) Aproximación a los fundamentos ideológicos del discurso político de Hugo Chávez Frías (1992-2000). Tese de mestrado em Ciência Política, Universidade Simón Bolívar.

LÓPEZ MAYA, Margarita. (2000) Organización y discurso del MVR y el PPT. Trabalho apresentado no Seminário "Venezuela: logros, problemas y desafíos del actual sistema político", realizado no Instituto de Estudios de Iberoamérica y Portugal da Universidade de Salamanca, $16-17$ de novembro. 
MAINWARING, Scott \& SCULLY, Timothy. (1995) Introduction: Party Systems in Latin America. In: MAINWARING, S. \& Scully, T.R., (eds.) Building Democratic Institutions: Party Systems in Latin America, Stanford, Stanford University Press.

MOLINA VEGA, José Enrique. (2000) Comportamiento electoral en Venezuela 1998-2000, cambio y continuidad, mimeo.

NJAIM, H., COMBELLAS, R. \& ALVÁREZ, A. (1998) Opinión pública y democracia en Venezuela, Caracas, Instituto de Estudios Políticos, Universidad Central de Venezuela.

PEREIRA, Valia. (1999) Tiempos de cambio en las actitudes políticas de los venezolanos. In: América Latina Hoy, $\mathrm{n}^{\circ} 21$, (monográfico Venezuela), abril.

ROBERTS, Kenneth. (1999) El neoliberalismo y la transformación del populismo en América Latina. In: MACKINNON, María Moira \& PETRONE, Alberto (eds.), Populismo y neopopulismo en América Latina, Buenos Aires, Ed. Eudeba, p. 375-408. 


\section{ANEXO}

\section{Texto das perguntas utilizadas}

Para começar, falemos da estabilidade da democracia em seu país. Em sua opinião, a democracia na Venezuela é hoje: muito estável, bastante estável, pouco estável ou nada estável?

\begin{tabular}{|c|c|}
\hline Muito estável & 1 \\
\hline Bastante estável & 2 \\
\hline Pouco estável & 3 \\
\hline Nada estável & 4 \\
\hline N.S. & 8 \\
\hline N.R. & 9 \\
\hline
\end{tabular}

Com qual das duas frases seguintes frases você está mais de acordo?

A democracia é preferível a qualquer outra forma de governo

Em contextos de crise econômica e instabilidade política, um governo autoritário pode ser preferível a um democrático

N.S.
N.n.
N.R.

$\mathrm{Na}$ atualidade, há uma série de temas que podem representar uma ameaça ou um risco para a consolidação da democracia no México. Dos seguintes temas que vou mencionar, até que ponto: muito, bastante, pouco ou nada, você crê que são hoje uma ameaça para a democracia mexicana?

\begin{tabular}{|c|c|c|c|c|c|c|}
\hline & Muito & Bastante & Pouco & Nada & NS & NR \\
\hline $\begin{array}{l}\text { As relações entre as forças armadas e o } \\
\text { governo }\end{array}$ & 1 & 2 & 3 & 4 & 8 & 9 \\
\hline A crise econômica & 1 & 2 & 3 & 4 & 8 & 9 \\
\hline O terrorismo e a violência política & 1 & 2 & 3 & 4 & 8 & 9 \\
\hline $\begin{array}{l}\text { O mau funcionamento do poder } \\
\text { judiciário }\end{array}$ & 1 & 2 & 3 & 4 & 8 & 9 \\
\hline O narcotráfico & 1 & 2 & 3 & 4 & 8 & 9 \\
\hline A dívida externa & 1 & 2 & 3 & 4 & 8 & 9 \\
\hline $\begin{array}{l}\text { A insegurança dos cidadãos(a } \\
\text { delinqüência, os assaltos e roubos) }\end{array}$ & 1 & 2 & 3 & 4 & 8 & 9 \\
\hline A pobreza e marginalidade & 1 & 2 & 3 & 4 & 8 & 9 \\
\hline O desinteresse do povo pela política & 1 & 2 & 3 & 4 & 8 & 9 \\
\hline
\end{tabular}


Mudando de tema. Há pessoas que dizem que sem partidos não pode haver democracia. Até que ponto: muito, bastante, pouco ou nada, você está de acordo com esta afirmação?

\begin{tabular}{|c|c|}
\hline Muito de acordo & 1 \\
\hline Bastante de acordo & 2 \\
\hline Pouco de acordo & 3 \\
\hline Nada de acordo & 4 \\
\hline N.S. & 8 \\
\hline N.R. & 9 \\
\hline
\end{tabular}

Em um contexto de pluralismo e ampla competição partidária, até que ponto, muito, bastante, pouco ou nada, você está de acordo com a afirmação de que as eleições são sempre o melhor meio para expressar certas determinadas preferências políticas?

$\begin{array}{cc}\text { Muito de acordo } & 1 \\ \text { Bastante de acordo } & 2 \\ \text { Pouco de acordo } & 3 \\ \text { Nada de acordo } & 4 \\ \text { N.S. } & 8 \\ \text { N.R. } & 9 \\ \text { N. } & \end{array}$

$\mathrm{Na}$ atualidade, discute-se bastante sobre o papel do Estado. Neste sentido, você poderia me dizer se está mais de acordo ou mais em desacordo com cada uma das seguintes afirmações?

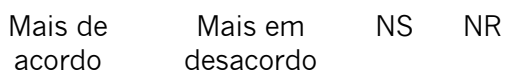

Em uma sociedade tão complexa como a atual, o Estado é desacordo incapaz de solucionar de maneira eficaz os problemas dos cidadãos

A intervenção do Estado na vida socioeconômica é a única maneira possível de reduzir as desigualdades sociais 
A seguir, gostaria de conhecer sua opinião sobre uma série de funções tradicionais do Estado. Pensando en termos gerais, diga-me, para cada uma delas, que grau de intervenção muito, bastante, pouco ou nenhuma, deveria assumir o Estado?

\begin{tabular}{|c|c|c|c|c|c|c|}
\hline & Muito & Bastante & Pouco & Nenhuma & NS & NR \\
\hline Controle dos preços & 1 & 2 & 3 & 4 & 8 & 9 \\
\hline $\begin{array}{l}\text { Dar cobertura de seguro de } \\
\text { desemprego }\end{array}$ & 1 & 2 & 3 & 4 & 8 & 9 \\
\hline
\end{tabular}

Como o sr. se lembra, quando se fala de política, se utilizam normalmente as expressões esquerda e direita. Neste cartão há uma série de casas que vão de esquerda a direita. Em que casa você se colocaria levando em conta suas idéias políticas?

Esquerda

$\begin{array}{llllllllll}01 & 02 & 03 & 04 & 05 & 06 & 07 & 08 & 09 & 10\end{array}$

E, nesta mesma escala, onde você situaria seu próprio partido?

Esquerda

01

02

03

04

05

06

07

08

09

Direita

Qual é sua opinião pessoal sobre o divórcio?

Totalmente a favor

Se deveriam ampliar os casos regulados pela legislação vigente

Só se deveria admitir nos casos regulados pela legislação vigente

Se deveriam limitar os casos regulados pela legislação vigente

Totalmente contra

N.R.

E sua opinião pessoal sobre o aborto?

Totalmente a favor

\begin{tabular}{|c|c|}
\hline Totalmente a favor & 1 \\
\hline Se deveriam ampliar os casos regulados pela legislação vigente & 2 \\
\hline Só se deveria admitir nos casos regulados pela legislação vigente & 3 \\
\hline Se deveriam limitar os casos regulados pela legislação vigente & 4 \\
\hline Totalmente contra & 5 \\
\hline N.R. & 9 \\
\hline
\end{tabular}

1

2

3

4

5

